\title{
CANTOS DE SOLEDADES Y CANTES POR SOLEARES: ANÁLISIS FILOLÓGICO
}

\author{
Miguel Ropero Núñez \\ Universidad de Sevilla
}

\section{Introducción.}

El primer y más prestigioso flamencólogo que conocemos fue, sin duda, Antonio Machado y Álvarez «Demofilo», padre de Antonio y Manuel. No podemos descartar que el saber flamenco de Demófilo ejerciera una importante influencia en el pensamiento y obra de sus hijos. Manuel Machado tiene un libro de poemas dedicado al cante y Antonio titula «Cante Hondo» un poema en el que capta maravillosamente la esencia del arte flamenco.

Este poema de A. Machado «Cante Hondo» aparece con el número XIV en un librito que él titula Soledades ${ }^{1}$. Quizá alguien podría pensar que existe una cierta relación semántica entre «Cante Hondo» y Soledades, ya que uno de los cantes básicos del arte gitano-andaluz es la Soleá. R. Ferreres, en el Prólogo a su edición de este libro de A. Machado, insinúa que el nombre de la copla «soleá» pudo muy bien sugerirle el título «Soledades»:

«También tenía a mano, muy a mano, la copla popular: La Soleá, de las que su padre recogió buen número; tanto él como Manuel escribirán algunas» ${ }^{2}$.

Con estos datos podríamos concluir que Soledades es el título flamenco de este libro de Antonio Machado, que tiene, además, un poema dedicado expresa-

1 Nuestra cita corresponde a la edición de la Col. Universal, publicada en Madrid en 1919. Según indica el mismo A. Machado en el Prólogo, «este libro se publicó en 1907, y no es más que una segunda edición con adiciones, poco esenciales, del libro Soledades, dado a la estampa en 1903», (págs. $5-6)$. 21.

2 R. FERRERES, Prólogo a su edición de Soledades de A. Machado. Madrid, Taurus 1974, pág. 
mente al Cante Hondo. Esta hipótesis sobre el parentesco etimológico y semántico entre Soledades y Soleares vendría confirmado por las investigaciones del romanista K. Vossler en torno a la soledad en la poesía española: la palabra andaluza soleá, solear, soleares, deriva de la castellana soledad que, a su vez, está emparentada con los vocablos soidade, soedade, suidade de la lengua lírica gallegoportuguesa ${ }^{3}$.

R. Molina, investigador cualificado del flamenco, comenta así estas ideas de K. Vossler:

«La difusión de la palabra «soleá» no tuvo lugar hasta el siglo XIX. Incluso el nombre propio de «Soledad» no se populariza hasta el siglo XVIII, al tomar incremento diversas advocaciones marianas procedentes del XVII, tales como Nuestra Señora de las Angustias, de los Dolores, de la Soledad, etc. En el siglo XVI y XVII se hablaba de «las soledades». Numerosas referencias alegadas por Vossler demuestran que hubo un canto "de soledades» ${ }^{4}$.

El mismo Diccionario de la Real Academia Española (DRAE) identifica la etimología y el significado de soleares y soledades, ya que considera a la soleá «forma popular andaluza de soledad». Con los datos ofrecidos por K. Vossler y por el DRAE, la hipótesis apuntada al principio de este trabajo se vería reforzada y ampliada de este modo: existe un parentesco musical, etimológico y literario entre las soledades y las soleares, emparentadas, a su vez, con las saudades gallegoportuguesas.

Nuestra opinión, sin embargo, no coincide con esta hipótesis. A pesar de que consideramos que A. Machado en su poema «Cante Hondo», inserto en el libro Soledades, penetra con extraordinaria sensibilidad e intuición flamenca en el núcleo semántico en torno al cual giran los temas flamencos -el amor y la muerte-, el título de su libro no tiene relación ninguna con el cante por soleares. Creemos, además, que no existe parentesco musical, ni etimológico ni lingüístico entre las soleares del cante gitano-andaluz y las soledades castellanas. Intentaremos justificar ordenadamente nuestras afirmaciones.

2. No existe parentesco musical entre el canto de soledades y el canto por soleares.

Las soleares, como hemos indicado antes, constituyen por sí solas uno de los pilares básicos del cante flamenco y, como tales, son autónomas e independientes de cualquier otro tipo de cantos. Los orígenes del cante flamenco son muy confusos y permanecen aún rodeados de misterios; en cuanto a las soleares, el único dato cierto, según hemos escuchado personalmente de Don Antonio Mairena, es que se trata de un cante gitano por su origen, por su estilo y por sus maestros. Geográficamente, los primeros cantes por soleá están localizados en Triana y Alcalá de Guadaira.

3 K. VOSSLER, La poesía de la Soledad en España. Buenos Aires, Ed. Losada, 1946.

4 R. MOLINA Y A. MAIRENA, Mundo y formas del cante flamenco. Sevilla, Lib. Al-Andalus, 1971, pág. 205. (1. Ed. en Madrid, Rev. de Occidente, 1963). 
S. Estébanez Calderón en sus Escenas andaluzas ${ }^{5}$ describe una fiesta «flamenca» en Triana, donde aparecen ya los nombres de muchos de los cantes flamencos. Este dato nos hace pensar en la posibilidad de que mucho antes de hacer su aparición pública en la Triana de 1840, el cante por soleares fuera cultivado en la intimidad del hogar gitano en la Baja Andalucía, que indiscutiblemente fue su cuna. La soleá, además, es un cante festero; tiene su origen muy probablemente en los cantes de jaleo; por consiguiente debemos descartar su parentesco musical con el canto «de soledades» o «de saudades» alegado por K. Vossler y recogido en el DRAE en la 4. acepción de soledad: "Tonada andaluza de carácter melancólico, en compás de tres por ocho» ${ }^{6}$. Si la soleá, desde el punto de vista musical, es un cante festero, resulta contradictorio definirla como «tonada de carácter melancólico». Esto no excluye que la interpretación de una soleá por parte de un determinado cantaor tenga alguna vez carácter melancólico o triste. Lo que no se debe es atribuirle exclusivamente al cante por soleá el carácter de melancólico, cuando puede ser también un cante alegre y festero por su música y por su tema, como veremos más adelante.

R. Molina, que ha estudiado a fondo junto con A. Mairena el origen musical de las soleares, concluye:

«Dichas «soledades», ausencias o nostalgias, estuvieron emparentadas con las «soidades» gallego-portuguesas, mas no con nuestras «soleares» gitanas» ${ }^{7}$.

3. No existe parentesco «de orden literario» entre los cantos de soledades y los cantos por soleares.

Hemos citado con frecuencia a R. Molina, cuyos argumentos nos han servido hasta ahora para confirmar nuestras opiniones, dadas sus cualidades de poeta y profundo conocedor del flamenco. Sin embargo, desde el punto de vista lingüístico que ahora nos ocupa, no coincidimos con él en algunos aspectos.

Dice R. Molina:

«Al negar parentesco pensamos en el musical, pues en el orden literario pudieran descubrirse evidentes analogías que no se le pasaron por alto ni al mismo Vossler» ${ }^{8}$.

En un estudio como el que nos ocupa, es necesario precisar bien los conceptos y términos y delimitar con exactitud el campo y punto de vista desde el cual investigamos para evitar conclusiones inexactas y malentendidos. Por tanto, al hablar de que no existe parentesco «de orden literario» entre soledades y soleares la exigencia de coherencia metodológica que nos hemos impuesto nos obliga a

5 S. ESTEBANEZ CALDERÓN, Escenas andaluzas. Madrid, Austral, 1960 (4. ed.) págs. 111-123.

6 DRAE, Vigésima Edición, 1984.

7 R. MOLINA Y A. MAIRENA, Mundo y formas del cante flamenco; op. cit. pág. 205.

8 Ibídem. 
distinguir diferentes niveles de estudio, ya que la expresión «de orden literario» empleada por R. Molina tiene un sentido muy amplio e incluye, a nuestro entender, aspectos fonético-fonológicos, morfosintácticos y léxico-semánticos.

Veamos, por separado, cada uno de estos aspectos.

\subsection{Aspectos fonético-fonológicos.}

En singular, el término soleá, como indica el Diccionario de la R. A. E., es la forma popular andaluza de soledad, ya que en el dialecto andaluz la [ $\delta$ ] final

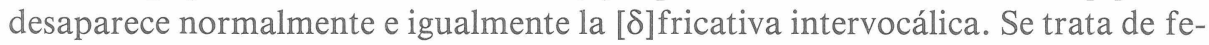
nómenos frecuentes no sólo en Andalucía sino tạmbién en casi toda la geografía lingüística del español. En este caso, el significante y el significado de ambos términos coinciden sustancialmente. Sólo existe una diferencia formal que corresponde a distintos tipos de lenguaje:

soledad: término del español estándar.

soleá: término popular andaluz.

En Andalucía y en el lenguaje del cante flamenco (como en muchas otras áreas del español actual) las formas soledad y su variante popular soleá se suelen usar bien como nombre común o bien como nombre propio. Así en Andalucía es popular la advocación mariana «Virgen de la Soledad» («de la Soleá»), que, además, encontramos documentada en algunas coplas de la Colección de cantes flamencos de Antonio Machado y Álvarez «Demófilo»:

$$
\begin{aligned}
& \text { «Vente conmigo y serás } \\
& \text { Capitana e mi barco, } \\
& \text { Binge e la Soleá» }{ }^{9} \text {. }
\end{aligned}
$$

También el nombre propio de mujer Soledad, correspondiente a esa advocación mariana, es común en Andalucía con la forma popular de Sole y Soleá, documentado varias veces en la selección de soleares recogidas por A. Machado y Álvarez:

«Soleá del arma mía, De noche te bengo a bé Poique no pueo e dia». (C.C.F. p. 68).

9 A. MACHADO Y ÁlVAREZ, Colección de cantes flamencos. Madrid, Ed. Demófilo, 1974 pág. 79. En adelante utilizaremos la sigla CCF para citar esta obra de A. Machado y Álvarez. La reedición de la Ed. Demófilo reproduce la edición original sevillana de 1881.

En cuanto a la «ortografía», respetamos en nuestras citas las grafías utilizadas por A. Machado y Álvarez o cualquier otro autor de cancioneros. Debemos, sin embargo, hacer notar la gran anarquía gráfica que hemos encontrado en los textos y cancionero flamencos. Una misma palabra o una misma expresión en un mismo cancionero aparece con una grafia determinada y, más adelante, de modo arbitrario, se escribe de otra forma. Hemos encontrado incluso en un mismo verso contradicciones gráficas como ésta:

$$
\begin{aligned}
& \text { « ¿Várgame los sielos! } \\
& \text { ¡Bárgame la tierra! } \\
& \text { ¡Lo que acarrea un testigo farso } \\
& \text { Y una mala lengua! }
\end{aligned}
$$

(Cantes flamencos, colección escogida por la Biblioteca de El Motín. Prólogo de A. Machado y Álvarez. Madrid, s. f., pág. 64. 
Naturalmente el valor significativo del significante soleá registrado aquí es muy diferente del que tiene el término soleá en el paradigma de los distintos tipos de cantes flamencos, como veremos al estudiar los aspectos léxico-semánticos en 3.3.

El plural de los términos soledades / soleares es el que nos plantea los primeros problemas de tipo fonológico: la presencia del fonema /r/ en el término andaluz donde el término castellano mantiene el fonema /d/ nos hace sospechar que se trata de términos diferentes, lo que nos llevará, a nivel léxico-semántico, a buscar distinta etimología al término soleares.

\subsection{Aspectos morfosintácticos.}

A este nivel de estudio nos interesa destacar la irregularidad en la formación del plural del término andaluz soleá:

$$
\begin{aligned}
& \text { SINGULAR / PLURAL } \\
& \text { soleá }
\end{aligned}
$$

El Diccionario de la R.A.E., precisamente porque se trata de una forma de plural anómala, lo indica junto al término soleá: «El plural es soleares». Sin embargo, el plural normal soleás también es utilizado por autores de reconocido prestigio en el mundo de las letras y del flamenco como R. Molina:

«Las bulerías, tientos y soleás abarcan toda la gama del amor» ${ }^{10}$.

Según nos ha aclarado A. Mairena se dice soleás cuando se trata de varias soleás del mismo estilo y soleares cuando se trata de soleares de distintos estilos.

Por otra parte, es interesante constatar cómo la forma del plural de la copla soleá, soleares, no puede aplicarse al nombre propio de mujer «Soledad», «Sole» o «Soleá». Así, no podemos decir «¡Qué morenas son esas Soleares!» refiriéndonos a dos mujeres andaluzas que se llaman «Soleá». Soleares es una forma de plural aplicable solamente al lenguaje específico del cante flamenco.

Todo esto nos hace pensar que realmente no existe un parentesco morfológico claro entre soledades y soleares. De todos modos, los estudios a nivel fonéticofonológico y morfosintáctico no nos dan respuestas totalmente satisfactorias y definitivas. Hay solamente indicios y numerosas incógnitas.

\subsection{Aspectos léxico-semánticos.}

Los cantos «de soledades» rẻseñados por $\mathrm{K}$. Vossler (Cfr. nota 3 ) son cantos de añoranzas, ausencias y nostalgias. También el Diccionario de la R.A.E. atribuye un parecido valor significativo al cante por soleares, ya que en la cuarta acepción de Soledad lo define como «tonada andaluza de carácter melancólico».

Sin embargo, los temas de los cantes por soleares no tratan específicamente ni de ausencias o nostalgias ni tienen forzosamente un carácter melancólico o triste. 
Quizá algunas soleares aluden a este tema, pero el concepto de soledad no es, en absoluto, eje semántico de los cantes por soleares.

De las 399 soleares de tres versos que recoge A. Machado y Álvarez en la CCF sólo cuatro nos han evocado el tema de la soledad:

$\begin{array}{ll}143 \quad & \text { En mi no reina alegría; } \\ & \text { Que, como te quiero tanto, } \\ & \text { Siento tu pena y la mía. (pág. 45) } \\ 243 \quad & \text { Pasé por tu puerta un día } \\ & \text { Y me acordé e los ratos } \\ \text { Que yo contigo tenía (pág. 63). } \\ \text { ¿Qué quieres tú que yo tenga? } \\ \text { Que te busco y no te encuentro, } \\ \text { Me ajoga la pena negra (pág. 65). } \\ \text { Yo se lo peí a Jesú, } \\ \text { Que por su muerte y pasión } \\ \text { Me yebe aonde estás tú (pág. 82). }\end{array}$

Una investigación léxica de frecuencias da los siguientes resultados: el nombre común soledad 'carencia de compañía' y la forma popular andaluza correspondiente soleá no aparecen ninguna vez en estas 399 coplas de soleares. Sólo en tres ocasiones - soleares $n .^{\circ} 274,275,254$ - aparece el término Soleá como advocación mariana o como nombre propio de mujer. En ninguna de estas tres coplas, sin embargo, se trata expresamente el tema de la soledad.

Más relación semántica y temática puede existir entre el tema de los cantos de soledades y el de los cantes por siguiriyas, que, por su naturaleza dramática, casi trágica, tratan temas más tristes (la muerte, por ejemplo). Las soleares tienen una temática muy variada: abarcan todos los matices de la vida humana con sus alegrías y sus penas. Sus letras, de estilo sencillo y espontáneo, reflejan experiencias vitales o manifiestan una actitud ante la vida y una visión muy peculiar de la realidad. Esto es común a todo el cante jondo, de ahí su dimensión existencial. A cada situación vital corresponde un estilo de soleá; unas veces es alegre, irónica, donde tienen cabida la broma, y el piropo; otras, a través de un estilo sentencioso o moralizador, condensará en breve copla una madura experiencia o un proverbio lleno de sabiduría; y otras veces será dramática, patética, donde el dolor, la desesperación, la «pena negra», adquieren dimensiones trágicas.

Dicen R. Molina y A. Mairena:

«La soleá no se casa con nada ni con nadie. Todo puede cantarse - y se cantapor soleá, desde lo más trágico hasta lo más anodino e inocente» ${ }^{11}$

Para dejar constancia de esta variedad temática, ofrecemos una brevísima antología de soleares de tres versos seleccionados de la C.C.F. ${ }^{12}$.

11 op. cit., pág. 208.

12 Cfr. págs. 25-87, n. 1-399. 
18 Anda y no presumas tanto Que otras mejores que tú Se quean pa bestí santos.

40 Arrímate a mi queré, Como las salamanquesas S'arriman a la paré.

79 Chiquilla, bente conmigo; Que no te fartará náa... Para andar encueros bibos.

81 Chiquiya, tú eres mu loca: Eres como las campañas, Que toito er mundo las toca.

115 En er barrio e Triana, Er que no sabe cantá, Sabe tocá bien las parmas.

116 Er dinero es un mareo: Aquer que tiene parné Es bonito aunque sea feo.

166 Los ojitos e tu cara Tan bonitos son e noche Como son por la mañana.

228 Por ber a mi mare diera Un deíyo de la mano, Er que más farta me hisiera.

241 ¿Para qué tanto yobé... Los ojitos tengo secos De sembrá y no cogé.

245 Quise cambiá y no quiso, Er pañuelo e lunares Por otro de fondo liso

289 Si er queré que puse en tí Lo hubiera puesto en un perro, Se biniera etrás e mi.

290 ¡Salero, biba lo mio, Salero, biba la mare Salero, que t'ha parío.

366 Yo me boy a gorbé loco Porque una biña que tengo La está bendimiando otro.

¿Dónde están la ausencia, la nostalgia, la melancolía? El tema de la soledad brilla por su ausencia.

En su tema, los cantos «de soledad» tienen como rasgo semántico específico el ser cantos de ausencia, melancólicos y tristes. Según los principios de la semántica operacional 'alegre' no sería un rasgo semántico pertinente aplicado a los cantos «de soledades» ya que la presencia de 'triste' excluye la presencia del rasgo se- 
mántico opuesto 'alegre‘. Sin embargo, a los cantes por soleares sí podemos aplicarles el adjetivo 'alegre' porque, en efecto, muchas soleares pueden tener un tema alegre y optimista. Así he encontrado el rasgo semántico 'alegre' atribuido a una soleá: "Y en Cádiz se atribuye a Paquirri el Guanté esta alegre soleá:

Metió en cañaverale

Los pájaros son clarine

Ar divino sol que sale» ${ }^{13}$.

Del análisis semántico de los cantos de «soledades» y de los cantes por soleares se puede deducir que ambos tienen un tema diferente y que soleares y soledades son palabras con distinto significado y que pertenecen a diferentes estructuras léxicas. Fonética y morfológicamente, como vimos, también tienen ciertas diferencias. Pues bien, si existe una diferencia de forma y de significado, es muy probable que tengan también distinta etimología. A mi entender, la etimología de soleá, soleares no hay que buscarla en soledad (de SOLITATEM) sino en solear, en Andalucía, 'acción de recoger la aceituna de soleo'. Soleo, según el DRAE, es un andalucismo que significa: «(De suelo) recolección de la aceituna caída del árbol naturalmente o derrribada por el aire».

Del mismo modo que existe entre los divesos tipos de cantes un cante de trilla o un cante de minas que se decía mientras se realizaban estos trabajos, existe un cante por soleares, que en un principio se cantaba mientras se hacía la faena de solear, esto es, coger aceitunas.

Este tipo de cante se ha convertido, al profesionalizarse el cante flamenco, en el actual cante por soleares, ya desligado de su primitivo contexto. M. Ríos Ruiz en su excelente Introducción al cante flamenco ofrece una interpretación etimológica parecida: «Creemos que no proviene de soledad: primero porque es un cante de diálogo, como muchos cantes jondos, y segundo porque consideramos que el cante por soleá nació como copla o trovo improvisado en los tajos de los campos bajoandaluces, entre las cuadrillas de gitanos escardadores de trigo o vareadores de aceitunas a pleno sol (no olvidemos que la recogida de aceituna se llama soleo, y que solear — de sol- significa asolear, tender una cosa a secar) (...) Cantar por soleá puede proceder de ese cantar al sol de los gitanos del campo» ${ }^{14}$.

No pretendo aquí ofrecer el origen indiscutible del término flamenco soleá, ya que muchas veces los nombres de los cantes no tienen una justificación etimológica científica; a veces el nombre puede habérsele puesto por cualquier circunstancia intrascendente, ajena incluso a la temática de la copla. Demófilo, por ejemplo, alude a que el nombre es debido a una mujer llamada Soledad ${ }^{15}$; igual podría haberse llamado Mercedes o Pastora... La petenera tiene su origen en la Paternera, cantaora de Paterna de Rivera; la jabera de una vendedora de habas (habera), etc. Que soleares tenga su origen en la faena de solear 'recoger la aceituna

13 R. Molina y A. Mairena, Mundo y formas del cante flamenco, pág. 124.

14 M. Ríos Ruiz, Introducción al cante flamenco. Madrid, 1972 pág. 76.

15 CCF., Prólogo, pág. 13. 
de soleo', o en el cantar a pleno sol de los gitanos bajoandaluces o a cualquier otra circunstancia no entra dentro de los límites de este trabajo esclarecerlo definitivamente; lo que sí he intentado demostrar es que soleares y soledades pertenecen a distintos sistemas léxicos y tienen distinto valor semántico.

El término soleá, como forma popular andaluza, forma parte, por tanto, de dos paradigmas léxicos diferentes:

1. Del paradigma léxico relacionado semántica y etimológicamente con el término castellano soledad, esto es, aislamiento, apartamiento, separación, melancolía, ausencia, nostalgia, tristeza,... Como nombre propio formaría parte de los paradigmas léxicos correspondientes a las advocaciones marianas o a los nombres propios de mujer: Angustias, Dolores, Soledad, etc.

El plural de soleá, formando parte de este paradigma léxico, no puede ser soleares.

2. Del paradigma léxico constituido por los nombres de los distintos tipos de cantes flamencos. En este caso no tiene relación semántica con el término castellano soledad y el plural de soleá es soleares. El término soleares es característico y específico del lenguaje del cante flamenco. Puede aparecer en castellano o en cualquier otra lengua, pero siempre como un préstamo del lenguaje peculiar del cante flamenco. En este caso, traducirlo por «soledades» no sería correcto. Decir «soledades» a las soleares (o «tocador» al tocaor, «hipido» al jipio, etc.) supondría introducir, desfigurados, unos elementos de un subsistema especial de lenguaje en otro sistema diferente, donde serían extraños e inexpresivos y donde estarían en interferencia semántica con sus homónimos de la lengua general. 
